\title{
ELOGIO DE LA LECTURA Y LA FICCIÓN DISCURSO NOBEL
}

\author{
Mario Vargas Llosa
}

Aprendí a leer a los cinco años, en la clase del hermano Justiniano, en el Colegio de la Salle, en Cochabamba (Bolivia). Es la cosa más importante que me ha pasado en la vida. Casi setenta años después recuerdo con nitidez cómo esa magia, traducir las palabras de los libros en imágenes, enriqueció mi vida, rompiendo las barreras del tiempo

Mario Vargas Llosa. Escritor y ensayista. Su primera publicación, Los Jefes (cuentos, 1959), obtuvo el premio Leopoldo Arias, al que le seguiría una larga lista de futuros reconocimientos y galardones; entre ellos el de la Crítica Española a La Ciudad de los Perros (1966) y el Nacional de Novela (Perú, 1997), el Internacional de Literatura Rómulo Gallegos por La Casa Verde (Venezuela, 1967) y el Miguel de Cervantes del Ministerio de Cultura de España (1994). En 1990 fue candidato a la presidencia de la República de Perú por el Frente Democrático (FREDEMO). Es miembro de la Academia Peruana de la Lengua y de la Real Academia Española y ha sido profesor visitante y escritor residente en varias universidades europeas y norteamericanas. Entre sus publicaciones más recientes se cuentan El Sueño del Celta (novela 2010); Travesuras de la Niña Mala (novela 2007); La Fiesta del Chivo (novela 2000); Nationalismus als neue Bedrohung, selección de ensayos políticos, publicado sólo en alemán (2000); El Lenguaje de la Pasión, selección de artículos de la serie Piedra de Toque (2001); Diario de Irak, selección de artículos sobre la guerra en Irak (2003); La Tentación de lo Imposible, ensayo sobre Los Miserables de Victor Hugo (2004); Un Demi-Siècle avec Borges, entrevista y ensayos sobre Borges (2004).

* Discurso de aceptación del Premio Nobel de Literatura ante la Academia de Suecia, en Estocolmo, pronunciado el 7 de diciembre de 2010. (C) Fundación Nobel 2010.

Palabras clave: Mario Vargas Llosa; Nobel de Literatura.

Estudios Públicos, 120 (primavera 2010). 
y del espacio y permitiéndome viajar con el capitán Nemo veinte mil leguas de viaje submarino, luchar junto a d'Artagnan, Athos, Portos y Aramís contra las intrigas que amenazan a la Reina en los tiempos del sinuoso Richelieu, o arrastrarme por las entrañas de París, convertido en Jean Valjean, con el cuerpo inerte de Marius a cuestas.

La lectura convertía el sueño en vida y la vida en sueño y ponía al alcance del pedacito de hombre que era yo el universo de la literatura. Mi madre me contó que las primeras cosas que escribí fueron continuaciones de las historias que leía pues me apenaba que se terminaran o quería enmendarles el final. $\mathrm{Y}$ acaso sea eso lo que me he pasado la vida haciendo sin saberlo: prolongando en el tiempo, mientras crecía, maduraba y envejecía, las historias que llenaron mi infancia de exaltación y de aventuras.

Me gustaría que mi madre estuviera aquí, ella que solía emocionarse y llorar leyendo los poemas de Amado Nervo y de Pablo Neruda, y también el abuelo Pedro, de gran nariz y calva reluciente, que celebraba mis versos, y el tío Lucho que tanto me animó a volcarme en cuerpo y alma a escribir aunque la literatura, en aquel tiempo y lugar, alimentara tan mal a sus cultores. Toda la vida he tenido a mi lado gentes así, que me querían y alentaban, y me contagiaban su fe cuando dudaba. Gracias a ellos y, sin duda, también, a mi terquedad y algo de suerte, he podido dedicar buena parte de mi tiempo a esta pasión, vicio y maravilla que es escribir, crear una vida paralela donde refugiarnos contra la adversidad, que vuelve natural lo extraordinario y extraordinario lo natural, disipa el caos, embellece lo feo, eterniza el instante y torna la muerte un espectáculo pasajero.

No era fácil escribir historias. Al volverse palabras, los proyectos se marchitaban en el papel y las ideas e imágenes desfallecían. ¿Cómo reanimarlos? Por fortuna, allí estaban los maestros para aprender de ellos y seguir su ejemplo. Flaubert me enseñó que el talento es una disciplina tenaz y una larga paciencia. Faulkner, que es la forma - la escritura y la estructura - lo que engrandece o empobrece los temas. Martorell, Cervantes, Dickens, Balzac, Tolstoi, Conrad, Thomas Mann, que el número y la ambición son tan importantes en una novela como la destreza estilística y la estrategia narrativa. Sartre, que las palabras son actos y que una novela, una obra de teatro, un ensayo, comprometidos con la actualidad y las mejores opciones, pueden cambiar el curso de la historia. Camus y Orwell, que una literatura desprovista de moral es 
inhumana y Malraux que el heroísmo y la épica cabían en la actualidad tanto como en el tiempo de los argonautas, la Odisea y la Ilíada.

Si convocara en este discurso a todos los escritores a los que debo algo o mucho sus sombras nos sumirían en la oscuridad. Son innumerables. Además de revelarme los secretos del oficio de contar, me hicieron explorar los abismos de lo humano, admirar sus hazañas y horrorizarme con sus desvaríos. Fueron los amigos más serviciales, los animadores de mi vocación, en cuyos libros descubrí que, aun en las peores circunstancias, hay esperanzas y que vale la pena vivir, aunque fuera sólo porque sin la vida no podríamos leer ni fantasear historias.

Algunas veces me pregunté si en países como el mío, con escasos lectores y tantos pobres, analfabetos e injusticias, donde la cultura era privilegio de tan pocos, escribir no era un lujo solipsista. Pero estas dudas nunca asfixiaron mi vocación y seguí siempre escribiendo, incluso en aquellos períodos en que los trabajos alimenticios absorbían casi todo mi tiempo. Creo que hice lo justo, pues, si para que la literatura florezca en una sociedad fuera requisito alcanzar primero la alta cultura, la libertad, la prosperidad y la justicia, ella no hubiera existido nunca. Por el contrario, gracias a la literatura, a las conciencias que formó, a los deseos y anhelos que inspiró, al desencanto de lo real con que volvemos del viaje a una bella fantasía, la civilización es ahora menos cruel que cuando los contadores de cuentos comenzaron a humanizar la vida con sus fábulas. Seríamos peores de lo que somos sin los buenos libros que leímos, más conformistas, menos inquietos e insumisos y el espíritu crítico, motor del progreso, ni siquiera existiría. Igual que escribir, leer es protestar contra las insuficiencias de la vida. Quien busca en la ficción lo que no tiene, dice, sin necesidad de decirlo, ni siquiera saberlo, que la vida tal como es no nos basta para colmar nuestra sed de absoluto, fundamento de la condición humana, y que debería ser mejor. Inventamos las ficciones para poder vivir de alguna manera las muchas vidas que quisiéramos tener cuando apenas disponemos de una sola.

Sin las ficciones seríamos menos conscientes de la importancia de la libertad para que la vida sea vivible y del infierno en que se convierte cuando es conculcada por un tirano, una ideología o una religión. Quienes dudan de que la literatura, además de sumirnos en el sueño de la belleza y la felicidad, nos alerta contra toda forma de opresión, pregúntense por qué todos los regímenes empeñados en controlar la conducta de los ciudadanos de la cuna a la tumba, la temen tanto que 
establecen sistemas de censura para reprimirla y vigilan con tanta suspicacia a los escritores independientes. Lo hacen porque saben el riesgo que corren dejando que la imaginación discurra por los libros, lo sediciosas que se vuelven las ficciones cuando el lector coteja la libertad que las hace posibles y que en ellas se ejerce, con el oscurantismo y el miedo que lo acechan en el mundo real. Lo quieran o no, lo sepan o no, los fabuladores, al inventar historias, propagan la insatisfacción, mostrando que el mundo está mal hecho, que la vida de la fantasía es más rica que la de la rutina cotidiana. Esa comprobación, si echa raíces en la sensibilidad y la conciencia, vuelve a los ciudadanos más difíciles de manipular, de aceptar las mentiras de quienes quisieran hacerles creer que, entre barrotes, inquisidores y carceleros viven más seguros y mejor.

La buena literatura tiende puentes entre gentes distintas y, haciéndonos gozar, sufrir o sorprendernos, nos une por debajo de las lenguas, creencias, usos, costumbres y prejuicios que nos separan. Cuando la gran ballena blanca sepulta al capitán Ahab en el mar, se encoge el corazón de los lectores idénticamente en Tokio, Lima o Tombuctú. Cuando Emma Bovary se traga el arsénico, Anna Karenina se arroja al tren y Julián Sorel sube al patíbulo, y cuando, en El Sur, el urbano doctor Juan Dahlmann sale de aquella pulpería de la pampa a enfrentarse al cuchillo de un matón, o advertimos que todos los pobladores de Comala, el pueblo de Pedro Páramo, están muertos, el estremecimiento es semejante en el lector que adora a Buda, Confucio, Cristo, Alá o es un agnóstico, vista saco y corbata, chilaba, kimono o bombachas. La literatura crea una fraternidad dentro de la diversidad humana y eclipsa las fronteras que erigen entre hombres y mujeres la ignorancia, las ideologías, las religiones, los idiomas y la estupidez.

Como todas las épocas han tenido sus espantos, la nuestra es la de los fanáticos, la de los terroristas suicidas, antigua especie convencida de que matando se gana el paraíso, que la sangre de los inocentes lava las afrentas colectivas, corrige las injusticias e impone la verdad sobre las falsas creencias. Innumerables víctimas son inmoladas cada día en diversos lugares del mundo por quienes se sienten poseedores de verdades absolutas. Creíamos que, con el desplome de los imperios totalitarios, la convivencia, la paz, el pluralismo, los derechos humanos, se impondrían y el mundo dejaría atrás los holocaustos, genocidios, invasiones y guerras de exterminio. Nada de eso ha ocurrido. Nuevas 
formas de barbarie proliferan atizadas por el fanatismo y, con la multiplicación de armas de destrucción masiva, no se puede excluir que cualquier grupúsculo de enloquecidos redentores provoque un día un cataclismo nuclear. Hay que salirles al paso, enfrentarlos y derrotarlos. No son muchos, aunque el estruendo de sus crímenes retumbe por todo el planeta y nos abrumen de horror las pesadillas que provocan. No debemos dejarnos intimidar por quienes quisieran arrebatarnos la libertad que hemos ido conquistando en la larga hazaña de la civilización. Defendamos la democracia liberal, que, con todas sus limitaciones, sigue significando el pluralismo político, la convivencia, la tolerancia, los derechos humanos, el respeto a la crítica, la legalidad, las elecciones libres, la alternancia en el poder, todo aquello que nos ha ido sacando de la vida feral y acercándonos — aunque nunca llegaremos a alcanzarla - a la hermosa y perfecta vida que finge la literatura, aquella que sólo inventándola, escribiéndola y leyéndola podemos merecer. Enfrentándonos a los fanáticos homicidas defendemos nuestro derecho a soñar y a hacer nuestros sueños realidad.

En mi juventud, como muchos escritores de mi generación, fui marxista y creí que el socialismo sería el remedio para la explotación y las injusticias sociales que arreciaban en mi país, América Latina y el resto del Tercer Mundo. Mi decepción del estatismo y el colectivismo y mi tránsito hacia el demócrata y el liberal que soy — que trato de serfue largo, difícil, y se llevó a cabo despacio y a raíz de episodios como la conversión de la Revolución Cubana, que me había entusiasmado al principio, al modelo autoritario y vertical de la Unión Soviética, el testimonio de los disidentes que conseguía escurrirse entre las alambradas del Gulag, la invasión de Checoeslovaquia por los países del Pacto de Varsovia, y gracias a pensadores como Raymond Aron, Jean-François Revel, Isaiah Berlin y Karl Popper, a quienes debo mi revalorización de la cultura democrática y de las sociedades abiertas. Esos maestros fueron un ejemplo de lucidez y gallardía cuando la intelligentsia de Occidente parecía, por frivolidad u oportunismo, haber sucumbido al hechizo del socialismo soviético, o, peor todavía, al aquelarre sanguinario de la revolución cultural china.

De niño soñaba con llegar algún día a París porque, deslumbrado con la literatura francesa, creía que vivir allí y respirar el aire que respiraron Balzac, Stendhal, Baudelaire, Proust, me ayudaría a convertirme en un verdadero escritor, que si no salía del Perú sólo sería un seudo 
escritor de días domingos y feriados. Y la verdad es que debo a Francia, a la cultura francesa, enseñanzas inolvidables, como que la literatura es tanto una vocación como una disciplina, un trabajo y una terquedad. Viví allí cuando Sartre y Camus estaban vivos y escribiendo, en los años de Ionesco, Beckett, Bataille y Cioran, del descubrimiento del teatro de Brecht y el cine de Ingmar Bergman, el TNP de Jean Vilar y el Odéon de Jean Louis Barrault, de la Nouvelle Vague y le Nouveau Roman y los discursos, bellísimas piezas literarias, de André Malraux, y, tal vez, el espectáculo más teatral de la Europa de aquel tiempo, las conferencias de prensa y los truenos olímpicos del general de Gaulle. Pero, acaso, lo que más le agradezco a Francia sea el descubrimiento de América Latina. Allí aprendí que el Perú era parte de una vasta comunidad a la que hermanaban la historia, la geografía, la problemática social y política, una cierta manera de ser y la sabrosa lengua en que hablaba y escribía. Y que en esos mismos años producía una literatura novedosa y pujante. Allí leí a Borges, a Octavio Paz, Cortázar, García Márquez, Fuentes, Cabrera Infante, Rulfo, Onetti, Carpentier, Edwards, Donoso y muchos otros, cuyos escritos estaban revolucionando la narrativa en lengua española y gracias a los cuales Europa y buena parte del mundo descubrían que América Latina no era sólo el continente de los golpes de Estado, los caudillos de opereta, los guerrilleros barbudos y las maracas del mambo y el chachachá, sino también ideas, formas artísticas y fantasías literarias que trascendían lo pintoresco y hablaban un lenguaje universal.

De entonces a esta época, no sin tropiezos y resbalones, América Latina ha ido progresando, aunque, como decía el verso de César Vallejo, todavía Hay, hermanos, muchísimo que hacer. Padecemos menos dictaduras que antaño, sólo Cuba y su candidata a secundarla, Venezuela, y algunas seudodemocracias populistas y payasas, como las de Bolivia y Nicaragua. Pero en el resto del continente, mal que mal, la democracia está funcionando, apoyada en amplios consensos populares, $\mathrm{y}$, por primera vez en nuestra historia, tenemos una izquierda y una derecha que, como en Brasil, Chile, Uruguay, Perú, Colombia, República Dominicana, México y casi todo Centroamérica, respetan la legalidad, la libertad de crítica, las elecciones y la renovación en el poder. Ése es el buen camino y, si persevera en él, combate la insidiosa corrupción y sigue integrándose al mundo, América Latina dejará por fin de ser el continente del futuro y pasará a serlo del presente. 
Nunca me he sentido un extranjero en Europa, ni, en verdad, en ninguna parte. En todos los lugares donde he vivido, en París, en Londres, en Barcelona, en Madrid, en Berlín, en Washington, Nueva York, Brasil o la República Dominicana, me sentí en mi casa. Siempre he hallado una querencia donde podía vivir en paz y trabajando, aprender cosas, alentar ilusiones, encontrar amigos, buenas lecturas y temas para escribir. No me parece que haberme convertido, sin proponérmelo, en un ciudadano del mundo, haya debilitado eso que llaman "las raíces", mis vínculos con mi propio país - lo que tampoco tendría mucha importancia-, porque, si así fuera, las experiencias peruanas no seguirían alimentándome como escritor y no asomarían siempre en mis historias, aun cuando éstas parezcan ocurrir muy lejos del Perú. Creo que vivir tanto tiempo fuera del país donde nací ha fortalecido más bien aquellos vínculos, añadiéndoles una perspectiva más lúcida, y la nostalgia, que sabe diferenciar lo adjetivo y lo sustancial y mantiene reverberando los recuerdos. El amor al país en que uno nació no puede ser obligatorio, sino, al igual que cualquier otro amor, un movimiento espontáneo del corazón, como el que une a los amantes, a padres e hijos, a los amigos entre sí.

Al Perú yo lo llevo en las entrañas porque en él nací, crecí, me formé, y viví aquellas experiencias de niñez y juventud que modelaron mi personalidad, fraguaron mi vocación, y porque allí amé, odié, gocé, sufrí y soñé. Lo que en él ocurre me afecta más, me conmueve y exaspera más que lo que sucede en otras partes. No lo he buscado ni me lo he impuesto, simplemente es así. Algunos compatriotas me acusaron de traidor y estuve a punto de perder la ciudadanía cuando, durante la última dictadura, pedí a los gobiernos democráticos del mundo que penalizaran al régimen con sanciones diplomáticas y económicas, como lo he hecho siempre con todas las dictaduras, de cualquier índole, la de Pinochet, la de Fidel Castro, la de los talibanes en Afganistán, la de los imanes de Irán, la del apartheid de Africa del Sur, la de los sátrapas uniformados de Birmania (hoy Myanmar). Y lo volvería a hacer mañana si - el destino no lo quiera y los peruanos no lo permitan - el Perú fuera víctima una vez más de un golpe de estado que aniquilara nuestra frágil democracia. Aquella no fue la acción precipitada y pasional de un resentido, como escribieron algunos polígrafos acostumbrados a juzgar a los demás desde su propia pequeñez. Fue un acto coherente con mi convicción de que una dictadura representa el mal absoluto para un país, 
una fuente de brutalidad y corrupción y de heridas profundas que tardan mucho en cerrar, envenenan su futuro y crean hábitos y prácticas malsanas que se prolongan a lo largo de las generaciones demorando la reconstrucción democrática. Por eso, las dictaduras deben ser combatidas sin contemplaciones, por todos los medios a nuestro alcance, incluidas las sanciones económicas. Es lamentable que los gobiernos democráticos, en vez de dar el ejemplo, solidarizándose con quienes, como las Damas de Blanco en Cuba, los resistentes venezolanos, o Aung San Suu Kyi y Liu Xiaobo, que se enfrentan con temeridad a las dictaduras que sufren, se muestren a menudo complacientes no con ellos sino con sus verdugos. Aquellos valientes, luchando por su libertad, también luchan por la nuestra.

Un compatriota mío, José María Arguedas, llamó al Perú el país de "todas las sangres". No creo que haya fórmula que lo defina mejor. Eso somos y eso llevamos dentro todos los peruanos, nos guste o no: una suma de tradiciones, razas, creencias y culturas procedentes de los cuatro puntos cardinales. A mí me enorgullece sentirme heredero de las culturas prehispánicas que fabricaron los tejidos y mantos de plumas de Nazca y Paracas y los ceramios mochicas o incas que se exhiben en los mejores museos del mundo, de los constructores de Machu Picchu, el Gran Chimú, Chan Chan, Kuelap, Sipán, las huacas de La Bruja y del Sol y de la Luna, y de los españoles que, con sus alforjas, espadas y caballos, trajeron al Perú a Grecia, Roma, la tradición judeo-cristiana, el Renacimiento, Cervantes, Quevedo y Góngora, y la lengua recia de Castilla que los Andes dulcificaron. Y de que con España llegara también el África con su reciedumbre, su música y su efervescente imaginación a enriquecer la heterogeneidad peruana. Si escarbamos un poco descubrimos que el Perú, como el Aleph de Borges, es en pequeño formato el mundo entero. ¡Qué extraordinario privilegio el de un país que no tiene una identidad porque las tiene todas!

La conquista de América fue cruel y violenta, como todas las conquistas, desde luego, y debemos criticarla, pero sin olvidar, al hacerlo, que quienes cometieron aquellos despojos y crímenes fueron, en gran número, nuestros bisabuelos y tatarabuelos, los españoles que fueron a América y allí se acriollaron, no los que se quedaron en su tierra. Aquellas críticas, para ser justas, deben ser una autocrítica. Porque, al independizarnos de España, hace doscientos años, quienes asumieron el poder en las antiguas colonias, en vez de redimir al indio y hacerle jus- 
ticia por los antiguos agravios, siguieron explotándolo con tanta codicia y ferocidad como los conquistadores, y, en algunos países, diezmándolo y exterminándolo. Digámoslo con toda claridad: desde hace dos siglos la emancipación de los indígenas es una responsabilidad exclusivamente nuestra y la hemos incumplido. Ella sigue siendo una asignatura pendiente en toda América Latina. No hay una sola excepción a este oprobio y vergüenza.

Quiero a España tanto como al Perú y mi deuda con ella es tan grande como el agradecimiento que le tengo. Si no hubiera sido por España jamás hubiera llegado a esta tribuna, ni a ser un escritor conocido, y tal vez, como tantos colegas desafortunados, andaría en el limbo de los escribidores sin suerte, sin editores, ni premios, ni lectores, cuyo talento acaso — triste consuelo- descubriría algún día la posteridad. En España se publicaron todos mis libros, recibí reconocimientos exagerados, amigos como Carlos Barral y Carmen Balcells y tantos otros se desvivieron porque mis historias tuvieran lectores. Y España me concedió una segunda nacionalidad cuando podía perder la mía. Jamás he sentido la menor incompatibilidad entre ser peruano y tener un pasaporte español porque siempre he sentido que España y el Perú son el anverso y el reverso de una misma cosa, y no sólo en mi pequeña persona, también en realidades esenciales como la historia, la lengua y la cultura.

De todos los años que he vivido en suelo español, recuerdo con fulgor los cinco que pasé en la querida Barcelona a comienzos de los años setenta. La dictadura de Franco estaba todavía en pie y aún fusilaba, pero era ya un fósil en hilachas, y, sobre todo en el campo de la cultura, incapaz de mantener los controles de antaño. Se abrían rendijas y resquicios que la censura no alcanzaba a parchar y por ellas la sociedad española absorbía nuevas ideas, libros, corrientes de pensamiento y valores y formas artísticas hasta entonces prohibidos por subversivos. Ninguna ciudad aprovechó tanto y mejor que Barcelona este comienzo de apertura ni vivió una efervescencia semejante en todos los campos de las ideas y la creación. Se convirtió en la capital cultural de España, el lugar donde había que estar para respirar el anticipo de la libertad que se vendría. Y, en cierto modo, fue también la capital cultural de América Latina por la cantidad de pintores, escritores, editores y artistas procedentes de los países latinoamericanos que allí se instalaron, o iban y venían a Barcelona, porque era donde había que estar si uno quería ser un poeta, novelista, pintor o compositor de nuestro tiempo. Para 
mí, aquellos fueron unos años inolvidables de compañerismo, amistad, conspiraciones y fecundo trabajo intelectual. Igual que antes París, Barcelona fue una Torre de Babel, una ciudad cosmopolita y universal, donde era estimulante vivir y trabajar, y donde, por primera vez desde los tiempos de la guerra civil, escritores españoles y latinoamericanos se mezclaron y fraternizaron, reconociéndose dueños de una misma tradición y aliados en una empresa común y una certeza: que el final de la dictadura era inminente y que en la España democrática la cultura sería la protagonista principal.

Aunque no ocurrió así exactamente, la transición española de la dictadura a la democracia ha sido una de las mejores historias de los tiempos modernos, un ejemplo de como, cuando la sensatez y la racionalidad prevalecen y los adversarios políticos aparcan el sectarismo en favor del bien común, pueden ocurrir hechos tan prodigiosos como los de las novelas del realismo mágico. La transición española del autoritarismo a la libertad, del subdesarrollo a la prosperidad, de una sociedad de contrastes económicos y desigualdades tercermundistas a un país de clases medias, su integración a Europa y su adopción en pocos años de una cultura democrática, ha admirado al mundo entero y disparado la modernización de España. Ha sido para mí una experiencia emocionante y aleccionadora vivirla de muy cerca y a ratos desde dentro. Ojalá que los nacionalismos, plaga incurable del mundo moderno y también de España, no estropeen esta historia feliz.

Detesto toda forma de nacionalismo, ideología - o, más bien, religión - provinciana, de corto vuelo, excluyente, que recorta el horizonte intelectual y disimula en su seno prejuicios étnicos y racistas, pues convierte en valor supremo, en privilegio moral y ontológico, la circunstancia fortuita del lugar de nacimiento. Junto con la religión, el nacionalismo ha sido la causa de las peores carnicerías de la historia, como las de las dos guerras mundiales y la sangría actual del Medio Oriente. Nada ha contribuido tanto como el nacionalismo a que América Latina se haya balcanizado, ensangrentado en insensatas contiendas y litigios y derrochado astronómicos recursos en comprar armas en vez de construir escuelas, bibliotecas y hospitales.

No hay que confundir el nacionalismo de orejeras y su rechazo del "otro", siempre semilla de violencia, con el patriotismo, sentimiento sano y generoso, de amor a la tierra donde uno vio la luz, donde vivieron sus ancestros y se forjaron los primeros sueños, paisaje familiar de 
geografías, seres queridos y ocurrencias que se convierten en hitos de la memoria y escudos contra la soledad. La patria no son las banderas ni los himnos, ni los discursos apodícticos sobre los héroes emblemáticos, sino un puñado de lugares y personas que pueblan nuestros recuerdos y los tiñen de melancolía, la sensación cálida de que, no importa donde estemos, existe un hogar al que podemos volver.

El Perú es para mí una Arequipa donde nací pero nunca viví, una ciudad que mi madre, mis abuelos y mis tíos me enseñaron a conocer a través de sus recuerdos y añoranzas, porque toda mi tribu familiar, como suelen hacer los arequipeños, se llevó siempre a la Ciudad Blanca con ella en su andariega existencia. Es la Piura del desierto, el algarrobo y el sufrido burrito, al que los piuranos de mi juventud llamaban "el pie ajeno" - lindo y triste apelativo_-, donde descubrí que no eran las cigüeñas las que traían los bebes al mundo sino que los fabricaban las parejas haciendo unas barbaridades que eran pecado mortal. Es el Colegio San Miguel y el Teatro Variedades donde por primera vez vi subir al escenario una obrita escrita por mí. Es la esquina de Diego Ferré y Colón, en el Miraflores limeño — la llamábamos el Barrio Alegre—, donde cambié el pantalón corto por el largo, fumé mi primer cigarrillo, aprendí a bailar, a enamorar y a declararme a las chicas. Es la polvorienta y temblorosa redacción del diario La Crónica donde, a mis dieciséis años, velé mis primeras armas de periodista, oficio que, con la literatura, ha ocupado casi toda mi vida y me ha hecho, como los libros, vivir más, conocer mejor el mundo y frecuentar a gente de todas partes y de todos los registros, gente excelente, buena, mala y execrable. Es el Colegio Militar Leoncio Prado, donde aprendí que el Perú no era el pequeño reducto de clase media en el que yo había vivido hasta entonces confinado y protegido, sino un país grande, antiguo, enconado, desigual y sacudido por toda clase de tormentas sociales. Son las células clandestinas de Cahuide en las que con un puñado de sanmarquinos preparábamos la revolución mundial. Y el Perú son mis amigos y amigas del Movimiento Libertad con los que por tres años, entre las bombas, apagones y asesinatos del terrorismo, trabajamos en defensa de la democracia y la cultura de la libertad.

El Perú es Patricia, la prima de naricita respingada y carácter indomable con la que tuve la fortuna de casarme hace 45 años y que todavía soporta las manías, neurosis y rabietas que me ayudan a escribir. Sin ella mi vida se hubiera disuelto hace tiempo en un torbellino caótico y 
no hubieran nacido Álvaro, Gonzalo, Morgana ni los seis nietos que nos prolongan y alegran la existencia. Ella hace todo y todo lo hace bien. Resuelve los problemas, administra la economía, pone orden en el caos, mantiene a raya a los periodistas y a los intrusos, defiende mi tiempo, decide las citas y los viajes, hace y deshace las maletas, y es tan generosa que, hasta cuando cree que me riñe, me hace el mejor de los elogios: "Mario, para lo único que tú sirves es para escribir".

Volvamos a la literatura. El paraíso de la infancia no es para mí un mito literario sino una realidad que viví y gocé en la gran casa familiar de tres patios, en Cochabamba, donde con mis primas y compañeros de colegio podíamos reproducir las historias de Tarzán y de Salgari, y en la Prefectura de Piura, en cuyos entretechos anidaban los murciélagos, sombras silentes que llenaban de misterio las noches estrelladas de esa tierra caliente. En esos años, escribir fue jugar un juego que me celebraba la familia, una gracia que me merecía aplausos, a mí, el nieto, el sobrino, el hijo sin papá, porque mi padre había muerto y estaba en el cielo. Era un señor alto y buen mozo, de uniforme de marino, cuya foto engalanaba mi velador y a la que yo rezaba y besaba antes de dormir. Una mañana piurana, de la que todavía no creo haberme recobrado, mi madre me reveló que aquel caballero, en verdad, estaba vivo. Y que ese mismo día nos iríamos a vivir con él, a Lima. Yo tenía once años y, desde entonces, todo cambió. Perdí la inocencia y descubrí la soledad, la autoridad, la vida adulta y el miedo. Mi salvación fue leer, leer los buenos libros, refugiarme en esos mundos donde vivir era exaltante, intenso, una aventura tras otra, donde podía sentirme libre y volvía a ser feliz. Y fue escribir, a escondidas, como quien se entrega a un vicio inconfensable, a una pasión prohibida. La literatura dejó de ser un juego. Se volvió una manera de resistir la adversidad, de protestar, de rebelarme, de escapar a lo intolerable, mi razón de vivir. Desde entonces y hasta ahora, en todas las circunstancias en que me he sentido abatido o golpeado, a orillas de la desesperación, entregarme en cuerpo y alma a mi trabajo de fabulador ha sido la luz que señala la salida del túnel, la tabla de salvación que lleva al náufrago a la playa.

Aunque me cuesta mucho trabajo y me hace sudar la gota gorda, y, como todo escritor, siento a veces la amenaza de la parálisis, de la sequía de la imaginación, nada me ha hecho gozar en la vida tanto como pasarme los meses y los años construyendo una historia, desde su incierto despuntar, esa imagen que la memoria almacenó de alguna 
experiencia vivida, que se volvió un desasosiego, un entusiasmo, un fantaseo que germinó luego en un proyecto y en la decisión de intentar convertir esa niebla agitada de fantasmas en una historia. "Escribir es una manera de vivir", dijo Flaubert. Sí, muy cierto, una manera de vivir con ilusión y alegría y un fuego chisporroteante en la cabeza, peleando con las palabras díscolas hasta amaestrarlas, explorando el ancho mundo como un cazador en pos de presas codiciables para alimentar la ficción en ciernes y aplacar ese apetito voraz de toda historia que al crecer quisiera tragarse todas las historias. Llegar a sentir el vértigo al que nos conduce una novela en gestación, cuando toma forma y parece empezar a vivir por cuenta propia, con personajes que se mueven, actúan, piensan, sienten y exigen respeto y consideración, a los que ya no es posible imponer arbitrariamente una conducta, ni privarlos de su libre albedrío sin matarlos, sin que la historia pierda poder de persuasión, es una experiencia que me sigue hechizando como la primera vez, tan plena y vertiginosa como hacer el amor con la mujer amada días, semanas y meses, sin cesar.

Al hablar de la ficción, he hablado mucho de la novela y poco del teatro, otra de sus formas excelsas. Una gran injusticia, desde luego. El teatro fue mi primer amor, desde que, adolescente, vi en el Teatro Segura, de Lima, La Muerte de un Viajante, de Arthur Miller, espectáculo que me dejó traspasado de emoción y me precipitó a escribir un drama con incas. Si en la Lima de los cincuenta hubiera habido un movimiento teatral habría sido dramaturgo antes que novelista. No lo había y eso debió orientarme cada vez más hacia la narrativa. Pero mi amor por el teatro nunca cesó, dormitó acurrucado a la sombra de las novelas, como una tentación y una nostalgia, sobre todo cuando veía alguna pieza subyugante. A fines de los setenta, el recuerdo pertinaz de una tía abuela centenaria, la Mamaé, que, en los últimos años de su vida, cortó con la realidad circundante para refugiarse en los recuerdos y la ficción, me sugirió una historia. Y sentí, de manera fatídica, que aquella era una historia para el teatro, que sólo sobre un escenario cobraría la animación y el esplendor de las ficciones logradas. La escribí con el temblor excitado del principiante y gocé tanto viéndola en escena, con Norma Aleandro en el papel de la heroína, que, desde entonces, entre novela y novela, ensayo y ensayo, he reincidido varias veces. Eso sí, nunca imaginé que, a mis setenta años, me subiría (debería decir mejor me arrastraría) a un escenario a actuar. Esa temeraria aventura me hizo vivir por primera 
vez en carne y hueso el milagro que es, para alguien que se ha pasado la vida escribiendo ficciones, encarnar por unas horas a un personaje de la fantasía, vivir la ficción delante de un público. Nunca podré agradecer bastante a mis queridos amigos, el director Joan Ollé y la actriz Aitana Sánchez Gijón, haberme animado a compartir con ellos esa fantástica experiencia (pese al pánico que la acompañó).

La literatura es una representación falaz de la vida que, sin embargo, nos ayuda a entenderla mejor, a orientarnos por el laberinto en el que nacimos, transcurrimos y morimos. Ella nos desagravia de los reveses y frustraciones que nos inflige la vida verdadera y gracias a ella desciframos, al menos parcialmente, el jeroglífico que suele ser la existencia para la gran mayoría de los seres humanos, principalmente aquellos que alentamos más dudas que certezas, y confesamos nuestra perplejidad ante temas como la trascendencia, el destino individual y colectivo, el alma, el sentido o el sinsentido de la historia, el más acá y el más allá del conocimiento racional.

Siempre me ha fascinado imaginar aquella incierta circunstancia en que nuestros antepasados, apenas diferentes todavía del animal, recién nacido el lenguaje que les permitía comunicarse, empezaron, en las cavernas, en torno a las hogueras, en noches hirvientes de amenazas - rayos, truenos, gruñidos de las fieras-, a inventar historias y a contárselas. Aquel fue el momento crucial de nuestro destino, porque, en esas rondas de seres primitivos suspensos por la voz y la fantasía del contador, comenzó la civilización, el largo transcurrir que poco a poco nos humanizaría y nos llevaría a inventar al individuo soberano y a desgajarlo de la tribu, la ciencia, las artes, el derecho, la libertad, a escrutar las entrañas de la naturaleza, del cuerpo humano, del espacio y a viajar a las estrellas. Aquellos cuentos, fábulas, mitos, leyendas, que resonaron por primera vez como una música nueva ante auditorios intimidados por los misterios y peligros de un mundo donde todo era desconocido y peligroso, debieron ser un baño refrescante, un remanso para esos espíritus siempre en el quién vive, para los que existir quería decir apenas comer, guarecerse de los elementos, matar y fornicar. Desde que empezaron a soñar en colectividad, a compartir los sueños, incitados por los contadores de cuentos, dejaron de estar atados a la noria de la supervivencia, un remolino de quehaceres embrutecedores, y su vida se volvió sueño, goce, fantasía y un designio revolucionario: romper aquel confinamiento y cambiar y mejorar, una lucha para 
aplacar aquellos deseos y ambiciones que en ellos azuzaban las vidas figuradas, y la curiosidad por despejar las incógnitas de que estaba constelado su entorno.

Ese proceso nunca interrumpido se enriqueció cuando nació la escritura y las historias, además de escucharse, pudieron leerse y alcanzaron la permanencia que les confiere la literatura. Por eso, hay que repetirlo sin tregua hasta convencer de ello a las nuevas generaciones: la ficción es más que un entretenimiento, más que un ejercicio intelectual que aguza la sensibilidad y despierta el espíritu crítico. Es una necesidad imprescindible para que la civilización siga existiendo, renovándose y conservando en nosotros lo mejor de lo humano. Para que no retrocedamos a la barbarie de la incomunicación y la vida no se reduzca al pragmatismo de los especialistas que ven las cosas en profundidad pero ignoran lo que las rodea, precede y continúa. Para que no pasemos de servirnos de las máquinas que inventamos a ser sus sirvientes y esclavos. Y porque un mundo sin literatura sería un mundo sin deseos ni ideales ni desacatos, un mundo de autómatas privados de lo que hace que el ser humano sea de veras humano: la capacidad de salir de sí mismo y mudarse en otro, en otros, modelados con la arcilla de nuestros sueños.

De la caverna al rascacielos, del garrote a las armas de destrucción masiva, de la vida tautológica de la tribu a la era de la globalización, las ficciones de la literatura han multiplicado las experiencias humanas, impidiendo que hombres y mujeres sucumbamos al letargo, al ensimismamiento, a la resignación. Nada ha sembrado tanto la inquietud, removido tanto la imaginación y los deseos, como esa vida de mentiras que añadimos a la que tenemos gracias a la literatura para protagonizar las grandes aventuras, las grandes pasiones, que la vida verdadera nunca nos dará. Las mentiras de la literatura se vuelven verdades a través de nosotros, los lectores transformados, contaminados de anhelos y, por culpa de la ficción, en permanente entredicho con la mediocre realidad. Hechicería que, al ilusionarnos con tener lo que no tenemos, ser lo que no somos, acceder a esa imposible existencia donde, como dioses paganos, nos sentimos terrenales y eternos a la vez, la literatura introduce en nuestros espíritus la inconformidad y la rebeldía, que están detrás de todas las hazañas que han contribuido a disminuir la violencia en las relaciones humanas. A disminuir la violencia, no a acabar con ella. Porque la nuestra será siempre, por fortuna, una historia 
inconclusa. Por eso tenemos que seguir soñando, leyendo y escribiendo, la más eficaz manera que hayamos encontrado de aliviar nuestra condición perecedera, de derrotar a la carcoma del tiempo y de convertir en posible lo imposible.

Estocolmo, 7 de diciembre de 2010. 